\title{
Effect of commercial diving on ventilatory function
}

\author{
S J WATT
}

\begin{abstract}
From the Institute of Environmental and Offshore Medicine, University of Aberdeen, and Offshore Medical Support, Aberdeen, UK
\end{abstract}

\begin{abstract}
A retrospective analysis of spirometric data from divers attending for annual medical examination at intervals from three to nine years was carried out to examine the long term effect of diving on lung volumes. Those divers with records over a three or four year interval (group 1, $\mathrm{n}=224$ ) showed a mean reduction of forced vital capacity (FVC) of $240 \mathrm{ml}$; those with records over a five or more years interval (group $2, \mathrm{n}=123$ ) showed a reduction of FVC of $400 \mathrm{ml}$. These reductions remined significant when expressed as a percentage of predicted normal values. The reduction of FVC between records did not correlate with the diver's age, maximum operating depth, duration of diving career, or weight change but was positively correlated with the initial FVC. The reductions in FVC were similar in smokers and non-smokers. The change in forced expiratory volume in one second $\left(\mathrm{FEV}_{1}\right)$ followed a similar pattern but was less pronounced than the effect on FVC. The decline in FVC associated with diving occurs from values of FVC that are above the predicted normal; few values below predicted normal were observed. The effect may represent either a gradual return towards the predicted normal or a pathological reduction in lung volume.
\end{abstract}

The large lung volumes of commercial divers ${ }^{1}$ appear to result from adaptation rather than from selection. ${ }^{2}$ Simple spirometry often shows a greater increase of forced vital capacity (FVC) than of forced expiratory volume in one second $\left(\mathrm{FEV}_{1}\right)$ above the predicted normal and thus the FEV $/ F V C$ ratio is reduced. This reduced $F E V_{1} / F V C$ ratio may indicate airways obstruction, and studies of flow volume curves in divers have also suggested abnormalities of small airway function. ${ }^{34}$

Previous cross sectional studies of divers have shown that the increase in FVC above the predicted normal correlated best with the greatest depth at which the diver had worked (maximum operating depth) but also with the duration of his diving career. $^{15}$ No longitudinal studies have been reported, however, so the long term effect of diving on lung function remains unknown. This study analyses the data from divers' annual medical examinations to examine the effect of diving on simple indices of ventilatory function over periods of between three and nine years.

Received 14 November 1983

Accepted 19 December 1983

\section{Methods}

This was a retrospective study based on the records of commercial divers who had attended Offshore Medical Support for an annual medical examination. At this examination the diver's height and weight are recorded and the $F E V_{1}$ and FVC are measured by vitalograph, the trace being retained in the diver's medical records. The diver himself completes details of the diving and smoking history.

The FEV 1 and FVC were measured using two vitalograph machines concurrently. Both were regularly calibrated and serviced according to the manufacturers' recommendations. Nursing staff of Offshore Medical Support carried out the tests.

The records of all divers who had attended the diving medical service were available for the survey. Data were collected from the notes of those divers who had attended for annual medical examinations three or more years apart. Records were excluded if the vitalograph trace was unsatifactory-that is, when fewer than two FVC manoeuvres had been performed or where the diver had failed his medical on the basis of a poor $\mathrm{FEV}_{1}$ or FVC (usually a result of airways obstruction). Records were also excluded if the diver was not white or was not actively diving.

The maximum values of FEV 1 and FVC on each 
Table 1 Age, diving history, and smoking history (at time of second record) for divers in groups 1 and 2

\begin{tabular}{|c|c|c|c|c|}
\hline & \multicolumn{2}{|c|}{ Group $1(n=224)$} & \multicolumn{2}{|c|}{ Group $2(n=123)$} \\
\hline & $M e a n \pm S E$ & Range & $M e a n \pm S E$ & Range \\
\hline $\begin{array}{l}\text { Age (y) } \\
\text { Interval between records }(y) \\
\text { Duration of diving career }(y) \\
\text { Maximum operating depth (m) }\end{array}$ & $\begin{array}{c}30 \pm 0.3 \\
3 \cdot 5 \pm 0 \cdot 03 \\
7 \cdot 3 \pm 0.3 \\
144 \pm 3 \cdot 3\end{array}$ & $\begin{array}{c}22-45 \\
3-4 \\
3-24 \\
35-300\end{array}$ & $\begin{array}{c}33 \pm 0 \cdot 4 \\
5 \cdot 9 \pm 0 \cdot 09 \\
9 \cdot 8 \pm 0 \cdot 4 \\
166 \pm 3 \cdot 7\end{array}$ & $\begin{array}{l}23-45 \\
5-9 \\
5-26 \\
45-310\end{array}$ \\
\hline $\begin{array}{l}\text { Smoking history: } \\
\text { Smokers } \\
\text { Non-smokers } \\
\text { Unknown }\end{array}$ & $\begin{array}{l}78 \\
95 \\
51\end{array}$ & & $\begin{array}{l}41 \\
57 \\
25\end{array}$ & \\
\hline
\end{tabular}

Table 2 Spirometric data and weights at times of each record for divers of both groups 1 and 2. Data presented as mean \pm $S E$

\begin{tabular}{|c|c|c|c|c|c|c|}
\hline & \multicolumn{3}{|c|}{ Group $1(n=224)$} & \multicolumn{3}{|c|}{ Group $2(n=123)$} \\
\hline & Ist record & $2 n d$ record & $p$ & 1st record & $2 n d$ record & $p$ \\
\hline $\begin{array}{l}\text { FEV }(1) \\
\text { FVC (1) } \\
\text { FEV as \% predicted }\end{array}$ & $\begin{array}{l}4.51 \pm 0.39 \\
5.56 \pm 0.48\end{array}$ & $\begin{array}{l}4 \cdot 39 \pm 0.37 \\
5 \cdot 32 \pm 0.46\end{array}$ & $\begin{array}{l}<0.001 \\
<0.001\end{array}$ & $\begin{array}{l}4.49 \pm 0.48 \\
5.57 \pm 0.57\end{array}$ & $\begin{array}{l}4 \cdot 22 \pm 0.47 \\
5 \cdot 17 \pm 0.57\end{array}$ & $\begin{array}{l}<0.001 \\
<0.001\end{array}$ \\
\hline $\begin{array}{l}\text { normal } \\
\text { FVC as \% predicted }\end{array}$ & $115 \pm 0 \cdot 8$ & $115 \pm 0.08$ & NS & $116 \pm 1 \cdot 1$ & $113 \pm 1 \cdot 1$ & $<0.001$ \\
\hline $\begin{array}{l}\text { normal } \\
\text { FEV /FVC (\%) } \\
\text { Weight (kg) }\end{array}$ & $\begin{aligned} & 117 \pm 0.8 \\
& 81.4 \pm 0.4 \\
& 75.8 \pm 0.6\end{aligned}$ & $\begin{array}{l}114 \pm 0 \cdot 8 \\
82 \cdot 8 \pm 0.4 \\
77 \cdot 1 \pm 0.6\end{array}$ & $\begin{array}{l}<0.001 \\
<0.01 \\
<0.001\end{array}$ & $\begin{array}{r}119 \pm 1 \\
80.9 \pm 0.8 \\
76.3 \pm 0.8\end{array}$ & $\begin{array}{r}113 \pm 1 \\
81.9 \pm 0.6 \\
78.4 \pm 0.8\end{array}$ & $\begin{array}{l}<0.001 \\
\text { NS } \\
<0.001\end{array}$ \\
\hline
\end{tabular}

NS $=$ Not significant.

occasion (at ATPS) were obtained from the vitalograph traces and were compared with the predicted normal values from the Committee on Rating of Physical and Mental Impairment ${ }^{6}$ adapted from Kory et al. ${ }^{7}$ The absolute values of FEV and FVC, the percentage of the predicted normal $\mathrm{FEV}_{1}$ and FVC, together with the divers age, interval between records, weight, smoking history, duration of diving career, and maximum operating depth were col- lected from the records and stored in computer files for analysis by the Statistical Package for the Social Sciences. Statistical comparisons were by paired $t ?$ test, and significance was accepted at the $1 \%$ level.

\section{Results}

Satisfactory records were available from 347 divers. The divers were divided into two groups for analysis,

Table 3 Spirometric data and characteristics for smoking and non-smoking divers of group 1. Data presented as mean \pm $S E$ (range)

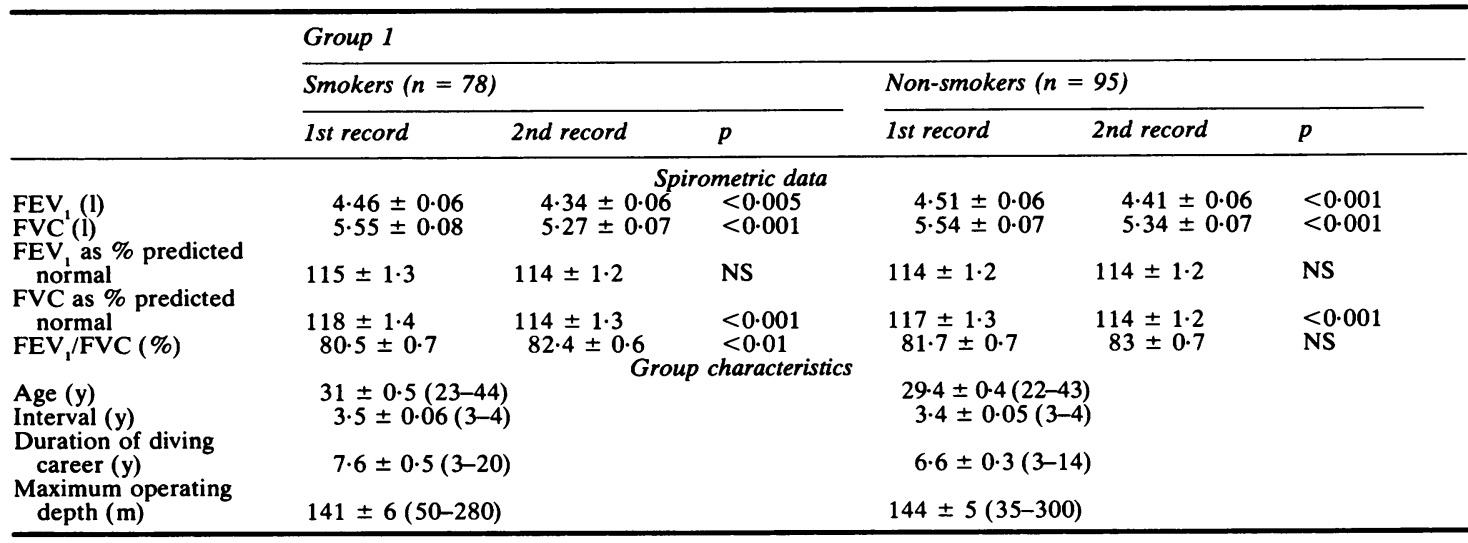

$\mathrm{NS}=$ Not significant . 
Table 4 Spirometric data and characteristics for smoking and non-smoking divers of group 2. Data presented as mean \pm $S E$ (range)

\begin{tabular}{|c|c|c|c|c|c|c|}
\hline & \multicolumn{6}{|l|}{ Group 2} \\
\hline & \multicolumn{3}{|c|}{ Smokers $(n=41)$} & \multicolumn{3}{|c|}{ Non-smokers $(n=57)$} \\
\hline & 1st record & 2nd record & $p$ & 1st record & 2nd record & $p$ \\
\hline \multirow{5}{*}{$\begin{array}{l}\mathrm{FEV}_{1}(\mathrm{l}) \\
\mathrm{FVCC}^{(1)} \\
\text { FEV }_{1} \text { as \% predicted } \\
\text { normal } \\
\text { FVC as \% predicted } \\
\text { normal } \\
\text { FEV }_{1} / \mathrm{FVC}(\%)\end{array}$} & \multicolumn{5}{|c|}{ Spirometric data } & \multirow{3}{*}{$\begin{array}{l}<0.001 \\
<0.001\end{array}$} \\
\hline & $4.36 \pm 0.07$ & $4 \cdot 13 \pm 0.08$ & $<0 \cdot 001$ & $4.57 \pm 0.07$ & $4.28 \pm 0.06$ & \\
\hline & $5.49 \pm 0.09$ & $5 \cdot 05 \pm 0.09$ & $<0.001$ & $5.64 \pm 0.09$ & $5 \cdot 23 \pm 0.08$ & \\
\hline & $113 \pm 1 \cdot 7$ & $111 \pm 1 \cdot 8$ & NS & $117 \pm 1 \cdot 6$ & $114 \pm 1 \cdot 6$ & $<0.02$ \\
\hline & $\begin{array}{l}118 \pm 1.7 \\
79.7 \pm 1.0\end{array}$ & \multirow{2}{*}{\multicolumn{2}{|c|}{$\begin{array}{cc}112 \pm 1 \cdot 6 & <0.001 \\
81 \cdot 1 \pm 0.9 & \text { NS } \\
\text { Group characteristics } & \end{array}$}} & $\begin{array}{l}119 \pm 1 \cdot 6 \\
81 \cdot 3 \pm 0 \cdot 8\end{array}$ & $\begin{array}{r}114 \pm 1 \cdot 3 \\
82 \pm 0 \cdot 9\end{array}$ & $\begin{array}{l}<0.001 \\
\text { NS }\end{array}$ \\
\hline \multirow{4}{*}{$\begin{array}{l}\text { Age }(y) \\
\text { Interval between } \\
\text { records }(y) \\
\text { Duration of diving } \\
\text { career }(y) \\
\text { Maximum operating } \\
\text { depth }(m)\end{array}$} & $33 \pm 0.7(25-43)$ & & & \multicolumn{2}{|c|}{$32 \cdot 6 \pm 0.6(25-45)$} & \\
\hline & \multicolumn{2}{|c|}{$5 \cdot 85 \pm 0 \cdot 1(5-8)$} & & \multicolumn{2}{|c|}{$6 \cdot 0 \pm 0 \cdot 1(5-9)$} & \\
\hline & \multicolumn{2}{|c|}{$9 \cdot 7 \pm 0 \cdot 6(5-18)$} & & \multicolumn{2}{|c|}{$9.6 \pm 0.6(5-26)$} & \\
\hline & \multicolumn{2}{|c|}{$166 \pm 4 \cdot 6(45-220)$} & & \multicolumn{2}{|c|}{$167 \pm 6 \cdot 4(50-310)$} & \\
\hline
\end{tabular}

NS $=$ Not significant.

those who had satisfactory records three or four years apart (group 1) and those who had satisfactory records five or more years apart (group 2). Table 1 shows the characteristics of the two groups. The group 2 divers were on average a little older and had been diving longer, but in other respects the groups were similar. There were more non-smokers than smokers in both groups and a small increase in weight had occurred during the interval between records in both groups.

Table 2 shows spirometric data from the two groups. There was a significant fall in $\mathrm{FEV}_{1}$ and FVC during the interval between records in both groups, FVC falling by an average of $240 \mathrm{ml}$ in group 1 and $400 \mathrm{ml}$ in group 2. These reductions remained significant when expressed as a percentage of the predicted normal except for $\mathrm{FEV}_{1}$ in group 1 .

The effect of smoking was examined by subdividing each group into smokers and non-smokers and the results for groups 1 and 2 are shown in tables 3 and 4 respectively. For both groups the smokers were similar to the non-smokers in age and diving history. There was a similar reduction in $\mathrm{FEV}_{1}$ and FVC in smokers and non-smokers of both groups, although smokers had lower FEV , $_{1}$ and FEV/FVC ratio than non-smokers in both groups.

The importance of maximum operating depth, duration of diving career, age, and weight gain was examined by correlating the variables with the change in FVC. There was no significant correlation between the change in FVC and any factor in either group. The change in FVC correlated positively with the initial FVC $(r=0.31, p<0.001$ group 1: $r=$ $0.32, p<0.001$ group 2); the FEV/FVC ratio showed a negative correlation with FVC at the time of both records for both groups.

\section{Discussion}

Normal lung function is essential for divers not only to be able to perform high levels of physical exertion but also to avoid the increased risk of pulmonary barotrauma associated with air trapping. Simple spirometry has, therefore, always formed a part of the commercial diver's annual medical examination. Several studies have shown that divers frequently have unusually large lung volumes ${ }^{135}$ and evidence from submarine escape instructors suggests that this is an adaptation ${ }^{2}$ rather than an effect of selection. There is also evidence that the large lung volumes are associated with an abnormality of expiratory airflow pattern suggestive of a small airway disorder. ${ }^{34}$ Nevertheless, no longitudinal data have been published and thus the long term effects on lung volumes and airflow remain unknown.

This study has shown a significant fall in FVC, about $240 \mathrm{ml}$ over a 3.5 year interval and $400 \mathrm{ml}$ over a 5.9 year interval. If this were maintained over a diving career of 15-20 years then a reduction of FVC of 1 to 1.51 might be expected. When compared with the predicted normal values and taking into account any effect of aging, the reduction in FVC remains significant. In fact recent data suggest that the reduction in FVC with aging, as assessed by the Kory nomogram, is probably an overestimate for the age range of the divers studied. Burrows et al suggest that the lung continues to grow until some time in the third decade and lung volumes may not 
start to decline until the fourth decade. ${ }^{8}$ This may have important implications for interpreting the changes seen in divers.

The reduction in FVC was not expected since previous cross sectional studies showed a positive correlation between FVC and diving exposure ${ }^{15}$; this study, by contrast, suggests that FVC falls with continued diving. This apparent difference may be explained by the continued growth of the lung in early adult life and because divers with longer careers may have started diving earlier. It seems probable that early in a diver's career diving tends to produce an increase in vital capacity. This effect may be more pronounced in younger divers whose lungs are more elastic and still developing. After lung development is complete, a gradual decline in vital capacity would be expected. On cessation of diving some additional decrease in vital capacity would also be expected. This explanation is supported by the finding of a significant correlation between the change in FVC and the initial FVC and also by the increased reduction in FVC noted by Davey et $\mathrm{al}^{4}$ in divers who reduced diving exposure. It was also predicted by Crosbie et al from cross sectional data. ${ }^{3}$ Although this study is subject to a healthy worker effect, few values below the predicted normal were observed and so the effect noted may represent a gradual return of lung volume toward the predicted normal after an initial hyperinflation. The possibility remains, however, that diving induces some structural change in the lung, either an interstitial lung disorder or an effect on small airways. Smoking does not appear to be an important factor in the decline in FVC as similar changes were seen in smokers and non-smokers. The absence of any significant correlation between the change in FVC with age or diving history may simply reflect the interaction and variability of these various factors. For example, duration of diving career is related to the divers age, and the number of dives in one year's diving is immensely variable.

Although the vitalograph is a relatively simple machine and the results depend on a variety of factors including the technique of performing the test, cooperation of the subject, and the physical effort used, several factors support the validity of the results of this study. The divers were all used to a variety of respiratory maneouvres, most had performed the test on many occasions, and all were highly motivated to do well. The results of the initial record are similar to those of Crosbie $e t a^{1}$ in a larger group of divers of a similar age range. The changes seen in group 1 are similar to, but less pronounced than, those in group 2 which occurred over a longer period, and the expected differences between smokers and non-smokers were observed.

This study has shown that the unusually large lungs of commercial divers decline in volume at a rapid rate. The data do not provide an explanation for this, and there is a need for more detailed pulmonary function studies over a prolonged period to assess the changes in lung volumes and airflow pattern associated with commercial diving and to identify those factors of importance in the diving history.

I thank the staff of Offshore Medical Support for their cooperation and help and the secretarial staff of the Institute of Environmental and Offshore Medicine for the preparation of the typescript.

\section{References}

${ }^{1}$ Crosbie WA, Clarke MB, Cox RAF, et al. Physical characteristics and ventilatory function of 404 commercial divers working in the North Sea. Br J Ind Med 1977;34:19-34.

${ }^{2}$ Carey CR, Schaefer KE, Alvis HJ. Effect of skin diving on lung volumes. J Appl Physiol 1956;8:519-23.

${ }^{3}$ Crosbie WA, Reed JW, Clarke MC. Functional characteristics of the large lungs found in commercial divers. J Appl Physiol 1979; 46:639-45.

${ }^{4}$ Davey IS, Cotes JE, Reed JW. Does diving exposure induce airflow obstruction? Clin Sci 1983;65:48p.

5 Cimsit M, Flook V. Pulmonary function in divers. In: Bachrach AJ, Matzen MM. Proceedings of the seventh symposium on underwater physiology 1981. Bethesda, Maryland: Undersea Medical Society, Inc. 249-55.

- Committee on Rating of Mental and Physical Impairment. Guides to evaluation of permanent impairment. The respiratory system. JAMA 1965;194:919-32.

${ }^{7}$ Kory RC, Callahan R, Boren HG, Syner JC. The veterans administration-army co-operative study of respiratory function. Am J Med 1961;30:243-58.

${ }^{8}$ Burrows B, Cline MG, Knudson RJ, Taussig LM, Leobowitz MD. A descriptive analysis of the growth and decline of the $\mathrm{FEV}_{1}$ and FVC. Chest 1983;83:717-24. 